\title{
CÓMO AFRONTAR EL DUELO EN LAS PERSONAS CON DISCAPACIDAD. UNA APROXIMACIÓN AL PROBLEMA
}

\section{How to face the duel in people with disabilities. An approach to the problem}

\author{
Eva Domingo Benito \\ Universidad de Burgos \\ José Luis Cuesta Gómez \\ Universidad de Burgos
}

Sergio Sánchez Fuentes

Universidad Autónoma de Madrid. Facultad de Formación del Profesorado. Ciudad Universitaria de Cantoblanco. 28049 Madrid

sergio.sanchezfuentes@uam.es

Recepción: 25 de septiembre de 2017

Aceptación definitiva: 21 de marzo de 2018

Resumen: La esperanza de vida de las personas con discapacidad intelectual ha aumentado considerablemente en los últimos años, y esta realidad supone que se incremente la posibilidad de vivir situaciones de duelo por la muerte de personas cercanas. Esta investigación pretende conocer cómo los jóvenes con discapacidad intelectual y su entorno viven los procesos de duelo causados por pérdidas relacionales. La muestra participante pertenece a la Asociación ASPANIAS (Burgos), y el método de recogida de información utilizado ha sido el de grupos de discusión con tres colectivos diferentes: jóvenes con discapacidad intelectual, profesionales y familiares. A través de los mismos, y de la categorización de la información en función de las ocho dimensiones de calidad de vida del modelo propuesto por Schalock y Verdugo, se ha llegado a la conclusión de que las personas con discapacidad intelectual experimentan procesos de duelo cuyas características dependen de numerosos factores. Esos procesos de duelo se complican porque van unidos a dificultades en expresión de sentimientos y desarrollo de estrategias de afrontamiento. Los autores concluyen que la formación recibida sobre el tema es nula 
y se aprecia una demanda, sobre todo práctica, que oriente y ayude al colectivo a generar su propia idea del concepto y actuar en consecuencia.

Palabras clave: discapacidad intelectual; duelo; pérdidas relacionales; calidad de vida; grupos de discusión.

АвsтRACт: The life expectancy of persons with intellectual disabilities has increased significantly during the last years, and this fact means that it is increased the possibility of experiencing mourning situations because the loss of close persons. Through this paper, it is expected to know how the young persons with intellectual disabilities (ID) and their environment experiment the processes of mourning caused because of relatives' loss. The participants belong to the association ASPANIAS in Burgos, and the method used to collect information was discussion groups with three different groups: young persons with intellectual disabilities, specialists and families. Hence considering these and the classification of the information depending on the eight domains of the Quality of Life paradigm constructed by Schalock and Verdugo, the research concludes that intellectual disability people experience mourning processes whose characteristics depend on numerous factors. These mourning processes become complex because they are joined to the trouble expressing their feelings and developing strategies to confront them. The instruction given to the ID people about this topic is non-existent and it is appreciated a demand, mainly a practical one, that guides and helps the collective to generate their own idea about the concept, to act consequentially and to talk it out.

KEY WORDs: intellectual disability; mourning; relatives' loss; quality of life; discussion groups.

\section{Introducción}

4 L PROCESO DE DUELO TRAS LA MUERTE DE UN SER QUERIDO genera una etapa difícil y confusión en la vida de las personas que va unido a una angustia emocional y a diversos problemas de adaptación a la nueva situación (McEvoy, Machale y Tierney, 2012). Además, esta circunstancia para las personas con discapacidad intelectual (en adelante DI), con una comprensión limitada del concepto de muerte, puede exacerbar la angustia y jugar un papel significativo en la prolongación del duelo.

Por ello, intentar comprender cómo viven o afrontan el duelo las personas con DI y conocer qué emociones experimentan son aspectos muy útiles para poder acompañarlas durante ese proceso y ayudar a sobrellevarlo de una manera normal. Y es que según la Asociación Americana de Discapacidad Intelectual y Desarrollo (en adelante, AAIDD) es importante destacar la conducta adaptativa (Verdugo, 2011) como característica necesaria para el funcionamiento de las personas con DI.

Varios autores coinciden en la importancia de que las personas con DI vivan el proceso de duelo como el resto de la población y tengan una visión real del ciclo vital, sin negarles la posibilidad de sufrir (Ruiz y Sainz, 2008; Romero, 2013). Este último añade que es necesario dar significado a lo sucedido para lograr la adaptación 
a la nueva situación y al día a día sin el ser querido, intentando seguir con la rutina habitual. Además, parece aceptado y no existen dudas de que las personas con discapacidad también experimentan procesos de duelo (Rodríguez, 2012), ya que, como afirma Gulbenkoglu (2007), el dolor es una emoción que se puede aplicar a todos los seres humanos, independientemente de su condición, y que actúa como respuesta a la pérdida del ser querido. Autores como Brickell y Munir (2008) y Roberts et al. (2016) consideran que el dolor en sí mismo no es patológico, y el duelo puede considerarse un proceso normal que incluye componentes cognitivos, emocionales, conductuales, físicos y sociales (Romero, 2013). Dichos componentes son mayores cuanto más apego, vínculo o dependencia exista con la persona fallecida (Tizón, 2004).

Gulbenkoglu (2007) propone que la manera de trabajar el duelo con las personas con discapacidad debe basarse precisamente en esa experiencia de pérdida, en lugar de en la comprensión del concepto de muerte. Por el contrario, en una investigación realizada por Rodríguez, Izuzquiza y De la Herrán (2015), se formula la idea de que la adquisición del concepto de muerte puede ayudar a comprender mejor los procesos involucrados en el desarrollo del duelo, y así evitar complicaciones. Estos autores concluyen que las personas con DI tienen una amplia variedad de opiniones, actitudes y creencias sobre la muerte, pero, también, que poseen dificultades en la comprensión de las dimensiones biológicas de la misma.

Rodríguez (2012: 15) afirma que "entre los 7 y 11 años los niños y niñas suelen tener adquirido este concepto de muerte biológica”, y que la evolución de dicho concepto puede no seguir las mismas pautas en niños y jóvenes con DI. Autores como Ruiz y Sainz (2008) también aluden a esta cuestión, asegurando que, generalmente, en la sociedad actual no se enseña a afrontar o desarrollar un sufrimiento normal ante la pérdida en la niñez o la adolescencia. Señalan que esto ocurre de igual manera, o incluso más acentuado, en personas con discapacidad, a quienes frecuentemente se les niega la posibilidad de aprenderlo además en la edad adulta.

Rodríguez, De la Herrán y Cortina (2012) realizan una revisión centrada en los antecedentes históricos de la pedagogía de la muerte en España. A partir de su estudio, sugieren el acompañamiento educativo como una metodología que ayude a evitar duelos complicados y dar normalidad a la muerte, aun siendo conscientes de que la pedagogía de la muerte puede ser una propuesta demasiado novedosa.

Puede afirmarse que uno de los fines perseguidos por la educación para la muerte y la formación en duelo en personas con DI es favorecer su inclusión en la sociedad, entendiendo dicha inclusión como una búsqueda de los recursos y medios adecuados para atender las diferencias entre personas (Martín y Sánchez, 2015). Por tanto, parece evidente que otra de las metas de la formación en duelo sea la mejora de la calidad de vida de las personas con DI y sus familias, ya que la prestación de apoyos se relaciona con un avance en los resultados personales de la misma (Baña, 2015).

Por otro lado, cabe destacar que, en los últimos años, ha aumentado la esperanza de vida de este colectivo debido a los novedosos avances técnicos, a las mejoras sanitarias y al creciente proceso de aceptación e inclusión en la sociedad de esta población (Rodríguez, 2012). El hecho de que su ciclo vital aumente conlleva un mayor número 
de experiencias, cambios y también pérdidas o fallecimientos de personas cercanas, como amigos o familiares (Rodríguez, De la Herrán e Izuzquiza, 2013a, 2013b). Sin embargo, como apunta Rodríguez (2012), parece que el número de investigaciones sobre duelo en personas con DI no ha crecido de forma paralela al aumento de su esperanza de vida.

Desgraciadamente, son escasas las investigaciones que abarcan los factores relacionados con la DI y sus procesos de duelo. Algunas de las razones que pueden justificar esta escasez son las creencias sobre su dificultad para aprender o comprender conceptos abstractos como el de la muerte, la presencia de algunos factores generalmente asociados a la discapacidad y la evitación del tema por parte de familiares o allegados (Wiese, Stancliffe, Read, Jeltes y Clayton, 2015). Sin embargo, según el modelo de calidad de vida presentado por Schalock y Verdugo (2007), el estado deseado de bienestar personal tiene propiedades éticas, universales y étnicas ligadas a la cultura, lo que determina que el proceso de duelo de las personas con DI debe estar contemplado en los procesos de intervención para mejorar sus capacidades de afrontamiento. De hecho, después de la descripción del modelo de 8 dimensiones, descrito por Schalock (1996) y Schalock y Verdugo (2002), esta ha venido siendo utilizada ampliamente para fines educativos relacionados con las personas con DI, tal como afirman Rodríguez, De la Herrán e Izuzquiza (2013b), aunque en escasa medida para trabajar el duelo en dicho colectivo.

Por lo tanto, el objetivo principal de este trabajo es conocer cómo los jóvenes con DI y su entorno viven los procesos de duelo causados por pérdidas relacionales, siguiendo el modelo de calidad de vida de Schalock y Verdugo (2002), para dar respuesta a la necesidad en los planes de formación sobre esta cuestión.

\section{Método}

\subsection{Diseño}

La técnica empleada para la investigación es el desarrollo de grupos focales. Mediante dicha técnica se hace posible recopilar información cuantitativa y cualitativa, aunque generalmente se asocia y es referente de esta última, por permitir un diálogo y una participación activa y crítica. El empleo de los grupos de discusión no solo permite el análisis de las experiencias de los participantes, sino también un análisis del contexto en el que estas tienen lugar (Barbour, 2013).

Los grupos de discusión representan una forma de entrevista en grupo cuyo fin es obtener datos sobre un tema específico. Además, dichas sesiones grupales están coordinadas por uno o más moderadores, cuya función es favorecer la interacción entre los participantes y la posterior recolección e interpretación de los datos. Es considerado un método útil para examinar "no sólo lo que piensan las personas sino también cómo piensan y por qué piensan de esa manera” (Kitzinger, 1995: 299).

Esta técnica permite acceder a diferentes testimonios o experiencias personales y también sacar partido a nuevas ideas que puedan surgir durante la conversación. Aporta 
cercanía, flexibilidad y la visión global de un grupo, pero también información a nivel individual, con diferentes opiniones sobre una misma cuestión. Se considera un buen método para tratar temas sensibles (Barbour, 2013), como ocurre en este caso con el tema de la muerte, el cual puede no resultar agradable.

Otra de las principales razones por las que se han escogido los grupos de discusión como técnica de investigación en este estudio es la facilidad que ofrece en el acceso a ciertos colectivos (Barbour, 2013), en este caso el de personas con discapacidad, quienes generalmente se desenvuelven mejor en una conversación dirigida que de forma escrita.

Además, los grupos de discusión, en este caso concreto, poseen la ventaja de que los participantes sientan pertenencia a un grupo con el que comparten ciertas características. A los familiares puede unirles el hecho de tener un hijo o un hermano con DI que haya vivido la muerte de un familiar cercano. Lo mismo ocurre con los profesionales, ya que todos forman parte del equipo de una misma asociación y han compartido experiencias profesionales similares. Por último, el grupo de usuarios tiene en común la pertenencia a la misma asociación y la experiencia de esa pérdida significativa para ellos. En el siguiente apartado se exponen las diferentes fases del proceso y cómo se ha llevado a cabo esa selección de la muestra.

\subsection{Selección de la muestra}

Para alcanzar los objetivos propuestos ha sido necesario contar con tres grupos de discusión diferentes: uno de padres, otro de profesionales y otro formado por el alumnado.

Para la selección de los mismos, el primer paso ha sido contactar con la pedagoga del centro ocupacional Puentesaúco de ASPANIAS, desde donde se ha facilitado el acceso al resto de personas y servicios.

El grupo de personas con DI ha sido seleccionado por la pedagoga del centro ajustándose a los siguientes criterios de inclusión: alumnado de ASPANIAS, de entre 16 y 25 años (edad a la que generalmente, ya se ha vivido alguna muerte cercana), de ambos sexos y diferentes grados de discapacidad intelectual, que hubieran sufrido la muerte de algún familiar, o ser querido cercano, en algún momento de su vida. Como criterio de exclusión se ha tenido en cuenta que no hubieran experimentado duelos complicados o tuvieran realmente problemas para hablar del tema y así evitar herir sensibilidades.

El grupo de familiares se ha seleccionado desde el servicio de ocio y familias de la asociación. En este caso, los criterios de inclusión han sido los siguientes: padres, madres o familiares próximos de personas jóvenes con DI de diferentes edades y grados, cuyos hijos o hijas fueran usuarios de la asociación, y que hubieran vivido la muerte de algún familiar cercano en algún momento de sus vidas. Otro de los criterios es el de que sus familiares con DI vivieran tanto en el servicio residencial de la asociación, como en casa, y así poder obtener mayores perspectivas. Una vez acordado esto, el 
coordinador del área de familias se ha encargado de la selección de los participantes que se ajustaran a las anteriores características.

Los criterios de inclusión solicitados para los profesionales han sido de perfiles de trabajadores tanto con experiencia en el centro, como personal incorporado recientemente, de diferentes edades y de ambos sexos. También que tuvieran diferentes formaciones académicas y que hubieran vivido durante el ejercicio de su profesión algún proceso de duelo de los usuarios. La selección también se ha realizado desde el área de ocio de ASPANIAS.

\subsection{Participantes}

El número total de participantes estuvo confirmado por los tres perfiles anteriormente descritos. Más concretamente, el grupo de personas con DI lo han formado un total de 12 personas. El grupo de familiares ha agrupado a 9 personas, entre ellos padres, madres y hermanos de personas con DI. En cuanto al grupo de profesionales, han participado 8 personas.

Por lo tanto, el número total de participantes en el estudio ha sido de 29 personas.

\subsection{Procedimiento}

Como ya se ha comentado, para la realización del presente estudio se ha contado con la colaboración de la asociación ASPANIAS de Burgos, que tiene como usuarios a personas con DI y sus familias.

Una vez decidida la metodología y la técnica de investigación, delimitados los objetivos y elaborado el guion de las preguntas para los grupos de discusión, el procedimiento es el siguiente y está dividido en tres fases principales:

- Primera fase: puesta en contacto con la asociación ASPANIAS y planteamiento de la propuesta. Una vez aceptada, se ha enviado toda la documentación pertinente al departamento de orientación de dicha asociación, desde donde se ha dirigido todo el proceso y accedido a los participantes de los grupos.

- Segunda fase: desarrollo de las tres sesiones con cada uno de los tres grupos de discusión, transcripción de la información y categorización de la misma.

- Tercera fase: elaboración de los resultados obtenidos de cada grupo y de las pertinentes conclusiones.

Con cada uno de los tres grupos mencionados, se ha llevado a cabo una sesión de entre 60 y 90 minutos, tiempo recomendable para el desarrollo de las mismas (Kitzinger, 1995). Cada sesión se ha grabado en audio para facilitar la posterior transcripción de datos. En cada uno de los grupos se ha empleado un guion de preguntas similar, pero con vocabulario adaptado en función de las características de los participantes.

Ediciones Universidad de Salamanca / CC BY-NC-ND

Siglo Cero, vol. 49 (4), n. ${ }^{\circ}$ 268, 2018, octubre-diciembre, pp. 51-68 


\section{TABLA 1. Guion de preguntas para los familiares}

1. ¿Cree que las personas con discapacidad tienen un proceso de duelo?

2. ¿Qué visión cree que tienen las personas con discapacidad intelectual sobre la muerte?

3. ¿Cómo se le comunica y cómo reacciona su hijo/a cuando un ser cercano ha fallecido?

4. ¿En algún momento pensaron ocultarle la noticia del fallecimiento del ser querido? ¿Por qué?

5. Su hijo/a ¿ ha experimentado algún síntoma de depresión, ansiedad, o algún problema de comportamiento en el hogar diferente al habitual tras la pérdida?

6. Su hijo/a ¿hace alusiones o participa cuando se recuerda a la persona fallecida? ¿Cree que es positivo?

7. Su hijo/a ¿ha mostrado o expresado sus sentimientos de manera adecuada y con confianza? ¿Cómo han evolucionado esos sentimientos tras la pérdida?

8. ¿Han establecido algunas pautas conjuntas con ASPANIAS para trabajar durante ese proceso de duelo?

9. ¿Alguna vez ha recibido su hijo/a formación sobre pedagogía de la muerte? ¿Dónde? ¿Con qué frecuencia?

10. Como padres ¿han recibido alguna formación para estar preparados si se diera el caso? $¿$ Consideran que existe información sobre duelo y discapacidad?

11. ¿Creen que recibir dicha formación evitaría procesos de duelo complicados y mejoraría la inclusión de su hijo/a en la comunidad? ¿Y su calidad de vida?

\section{TABLA 2. Guion de preguntas para los participantes con DI}

1. ¿Qué sabes sobre la muerte? ¿Crees que todo el mundo puede morir?

2. ¿Cómo nos sentimos cuando alguien muere? ¿Y en los días posteriores?

3. ¿Sabes a qué se llama proceso de duelo?

4. ¿Crees que vosotros tenéis un proceso de duelo cuando fallece un ser querido?

5. ¿Has vivido la muerte de algún ser querido o persona cercana?

6. ¿Qué hiciste cuando te lo comunicaron? ¿Quién te lo dijo? ¿Qué sentías?

7. ¿Te gusta hablar o recordar a la persona fallecida?

8. ¿Te has comportado de manera diferente después de la muerte de un ser querido?

9. ¿Tienes personas que te hayan ofrecido su apoyo y con las que poder hablar?

10. ¿Alguna vez te han hablado o has recibido formación sobre la muerte? ¿Dónde?

11. ¿Crees que saber más sobre el tema de la muerte puede ayudar a las personas a estar mejor cuando fallece un ser querido?

12. ¿Tener formación sobre la muerte ayuda a la integración en la comunidad de todas las personas? ¿Mejora vuestra calidad de vida?

\section{TABLA 3. Guion de preguntas para los profesionales}

1. ¿Qué visión cree que tienen las personas con discapacidad intelectual sobre la muerte? ¿Experimentan procesos de duelo?

2. ¿Alguna vez ha acompañado a algún usuario del centro en el proceso de duelo? ¿Cómo se realiza ese acompañamiento (pautas, protocolos que seguir...)? ¿Qué destacaría de esa experiencia?

3. ¿Quién suele comunicarle a la persona con discapacidad que un ser querido ha fallecido? ¿Cuál es la reacción de una persona con discapacidad ante esta noticia? 


\section{TABLA 3. Guion de preguntas para los profesionales (cont.)}

4. Durante ese proceso de duelo, ¿suelen presentar problemas de conducta en el centro o dificultad para relacionarse con el resto?

5. Como personas de referencia, ¿̇suelen pedirles ayuda los usuarios en algún momento? ¿Expresan sus sentimientos y emociones de manera adecuada y en confianza?

6. Como profesionales, ¿han recibido ustedes algún tipo de formación sobre duelo en alguna ocasión?

7. Los usuarios del centro, ¿tienen posibilidad de aprender aspectos sobre la muerte que les interesen?

8. ¿Reciben formación sobre pedagogía de la muerte? ¿Con qué frecuencia? ¿Consideran necesaria dicha formación?

9. ¿Se ofrece desde ASPANIAS algún recurso, servicio o apoyo específico tras la pérdida si así fuese necesario? ¿Cuáles?

10. ¿Establecen algún tipo de pauta conjunta con la familia?

11. ¿Educar sobre duelo mejora la calidad de vida de las personas con discapacidad? ¿Puede ayudar a evitar duelos complicados? ¿Favorece la inclusión de estas personas en la comunidad?

Las tres sesiones han seguido la misma estructura, comenzando con la presentación de la moderadora y también del tema y los objetivos de la investigación. Posteriormente, se les ha explicado la dinámica que debe seguir un grupo de discusión y la necesidad de grabar sus testimonios en audio. También en estos primeros minutos se les ha hecho entrega del consentimiento informado, documento en el que autorizan formar parte del proceso y en el que se comunica la absoluta confidencialidad del estudio y empleo de la información únicamente con fines académicos.

\subsection{Análisis de datos}

Se ha señalado que la metodología empleada en la investigación es de carácter cualitativo, pues lo que se pretende es la búsqueda de experiencias y percepciones que los diferentes participantes tienen sobre el duelo de las personas jóvenes con DI y sus reflexiones sobre ello.

Para el análisis y la codificación de datos, el software empleado ha sido el programa de computación cualitativo WEFT QDA 1.0 (Martínez, 2009). Esto ha permitido la creación de categorías y subcategorías para estructurar los resultados, debido a la numerosa información recabada, y así favorecer el análisis.

Se han tomado como categorías principales las ocho dimensiones de calidad de vida propuestas por Schalock y Verdugo (2002), y como subcategorías, los indicadores de las mismas. Dichas categorías se corresponden en gran medida con el principal objetivo de investigación, ya que lo que se persigue es mejorar la calidad de vida de las personas con discapacidad, también desde el ámbito del duelo. Además, se ha tenido en cuenta que las evaluaciones individuales de los usuarios de ASPANIAS también se realizan en base a las dimensiones de calidad de vida y cómo van progresando los usuarios en cada una de ellas trimestre a trimestre. 


\section{FIGURA 1. Categorías y subcategorías analizadas}

\begin{tabular}{|l|l|l|l|}
\hline 1. Bienestar físico & $\begin{array}{l}\text { Salud } \\
\text { Ocio y tiempo libre } \\
\text { Disfrute personal }\end{array}$ & 5. Desarrollo personal & $\begin{array}{l}\text { Educación/formación } \\
\text { Madurez } \\
\text { Resiliencia al cambio }\end{array}$ \\
\hline $\begin{array}{l}\text { 2. Bienestar } \\
\text { emocional }\end{array}$ & $\begin{array}{l}\text { Empatía } \\
\text { Emociones/sentimientos } \\
\text { Espiritualidad } \\
\text { Autoconcepto }\end{array}$ & 6. Bienestar material & $\begin{array}{l}\text { Objetos } \\
\text { Propiedad }\end{array}$ \\
\hline $\begin{array}{l}\text { 3. Relaciones } \\
\text { interpersonales }\end{array}$ & $\begin{array}{l}\text { Apoyos } \\
\text { Interacciones } \\
\text { Afrontamiento }\end{array}$ & 7. Autodeterminación & $\begin{array}{l}\text { Decisiones/elecciones } \\
\text { Valores }\end{array}$ \\
\hline 4. Inclusión social & $\begin{array}{l}\text { Participación } \\
\text { Roles } \\
\text { Ambiente }\end{array}$ & 8. Derechos & $\begin{array}{l}\text { Información } \\
\text { Educación } \\
\text { Privacidad/intimidad }\end{array}$ \\
\hline
\end{tabular}

\section{Resultados}

\subsection{Categoría de Bienestar físico}

Algunos de los participantes con DI han visitado a familiares enfermos en hospitales e identifican dicha enfermedad, lo cual podría decir que el aspecto físico de una persona puede servirles como indicador para suponer una muerte próxima. Participantes y profesionales coinciden en que cuando un familiar cercano fallece la persona con discapacidad siente síntomas de enfermedad en sí mismo o reconocen sentirse mal. A pesar de ello, en los tres grupos se ha observado que las personas con DI no piensan en su propia muerte ni en la de sus familiares y dedican sus pensamientos al disfrute personal y cotidiano. En cuanto a ocio y tiempo libre todos los grupos coinciden en que, cuando una persona cercana fallece, la persona con discapacidad añora las actividades o el tiempo que solían pasar juntos, llegando a señalar incluso que lo que realmente echan de menos es el realizar esa actividad y no a la persona en sí.

- Subcategoría de salud

- Participante 6: "Yo al de amigo no fui porque estaba mal también el chaval, del accidente y eso no estaba muy bien, en plan... no sé, le habían operado y eso y no tenía el rostro bien".

- Profesional 2: "Ellos si ven que su madre está en el hospital pasándolas canutas también saben que se va a morir, lo saben igual que tú. Hombre, que lo percibe y lo ve, ¿y qué haces tú?”.

- Profesional 1: "Pero de caer en una profunda depresión y después de un año seguir o peor vaya. Y bajas laborales y no poder volver a trabajar".

- Subcategoría de ocio y tiempo libre y disfrute personal

- Participante 1: "Pienso en ser joven de momento".

- Participante 9: "Pues mal porque es raro que no esté ella, porque cuando estaba ella hacíamos muchas cosas y ahora casi no voy al pueblo porque como también se murió mi abuela pues ya es como que ya no vamos al pueblo". 
- Familiar 7: "Yo no tengo coche, mi hermano sí que tenía y como le llevaba por ahí a muchos sitios pues siempre después decía, jopé, que pena que no está el tío que me llevaba a tal o sabes".

- Profesional 1: "Igual si esa actividad la realiza con otra persona igual tampoco lo nota”.

\subsection{Categoría de Bienestar emocional}

Se han hallado disparidad de opiniones. Los participantes con DI dicen comprender la tristeza ajena y haber experimentado ese sentimiento tras una pérdida e incluso haberlo expresado llorando. También afirman sentirse raros al recordar a la persona fallecida. Sin embargo, profesionales y familiares destacan la frialdad que muestran las personas con DI a la hora de expresar sus sentimientos en estas situaciones y creen que no saben cómo hacerlo por la falta de conocimientos sobre el tema de la muerte. Comentan que el autoconcepto de una persona con discapacidad puede ser similar al de un niño, aunque también señalan que la forma de vivenciar el duelo depende de la capacidad de afrontamiento de cada uno y el nivel de discapacidad. Los participantes también han hecho referencia a términos como la reencarnación o el más allá, en los cuales afirman creer.

- Subcategoría de empatía

- Participante 7: "Sí, sí que se nota pero yo intento como calmarle o yo qué sé, o cambio de tema para que no piense esas cosas".

- Profesional 3: “Al 70\% de las personas con discapacidad no se lo cuentan quizás porque piensan que les van a hacer un favor y en algún momento pues no es así”.

- Familiar 3: "Comprender la muerte depende del grado de discapacidad que tenga la persona”.

- Subcategoría de espiritualidad

- Participante 9: "Yo sí que creo en esas cosas, más que fantasmas yo diría espíritus”.

- Subcategoría de autoconcepto

- Participante 8: "Me sentía como que me faltaba alguien importante que me ayudara y todo eso".

- Profesional 4: "Si hubieran tenido una concepción más amplia, un concepto general de lo que es la muerte, lo que significa, lo que deja de significar o no sé, o se hayan podido crear su propio concepto pues bueno, quizás no hubieran sufrido tanto".

- Familiar 6: "Pero los padres tenemos la culpa de no enfocarles a ellos lo que es la muerte, no le explicamos”. 
- Subcategoría emociones/sentimientos

- Participante 1: "Yo creo que la persona que ha fallecido mejor no hablar de ella porque luego... porque cuando estás en el entierro ahí sientes dolor y si luego lo recuerdas pues te vuelve el dolor".

- Participante 3: "Lloraba, estaba triste, estaba tranquilo".

- Profesional 2: "Hay algunos que yo creo que no llegan ni a tener ningún duelo".

- Profesional 5: "Yo he visto algunos de niveles bajos decírselo y con una frialdad [...] Porque indudablemente también es verdad que una persona con un nivel severo pues puede tener unas reacciones muy primarias y dices, no elabora".

- Familiar 8: "Yo creo que los chicos estos tienen el sentimiento igual que los niños de 8 o 9 años cuando se muere un familiar o algún conocido o un amigo, no expresan el sentimiento profundo de la muerte”.

\subsection{Categoría de Relaciones interpersonales}

Las personas con DI identifican a sus padres como su principal figura de apoyo, y profesionales y familiares reconocen una demanda de ese apoyo por parte de los jóvenes cuando alguien fallece (aunque recurran a diversas estrategias para hacerlo). Profesionales y familiares señalan, además, que las interacciones con las personas con DI tras un fallecimiento son poco profundas y maduras y que suelen hacerlo mediante muchas preguntas. También se han encontrado resultados en cuanto a la falta de interacción a la hora de comunicar la noticia de padres a hijos, así como diferentes maneras de afrontamiento utilizadas por los participantes con DI cuando muere un ser querido.

- Subcategoría de apoyos

- Participante 8: "Si, me ayudaban mis padres".

- Profesional 6: "Hay veces que te dicen, se ha muerto mi madre, mi tía, mi primo, te va a contar pues bueno tal no sé qué y ya está pero como... te lo cuento y ya está”.

- Profesional 2: "Y luego por ejemplo los medios son muy curiosos. Hacen lo que les gusta, van con todos, que yo creo que también es como una llamada de atención”.

- Subcategoría de interacciones

- Participante 11: "Me lo dijeron 3 días después de que pasó y yo al principio no lo entendía porque me lo dijeron como de una forma muy rara”.

- Profesional 5: “Tienden a venir uno por uno a decírnoslo a todos”.

- Profesional 3: "Pero no te dicen quiero hablar contigo".

- Familiar 8: "Y cuando se muere uno, te hace 50.000 mil preguntas, ¿y qué pasa? ¿Y porque se ha muerto? ¿Y a dónde le entierran? ¿A dónde está ahora? ¿Ha estado en el hospital, ha estado en casa?”. 
- Subcategoría de afrontamiento

- Participante 9: "Yo me encierro en mi habitación y no sé, yo me pongo a escuchar música o yo qué sé y me relajo porque estar ahí, la gente sí te ayuda pero... a veces te agobian demasiado".

- Profesional 1: "Se bloquean".

\subsection{Categoría de Inclusión social}

Los participantes con DI han respondido no haber participado en ciertos actos ya que no habían sido informados de la muerte de un familiar, hecho que corroboran los familiares reconociendo que en ocasiones no les han dejado implicarse por miedo a enfrentarles a ello. El rol que adoptan en su mayoría las personas con DI es el de ser un apoyo para el resto ya que, según responden ellos mismos, el estado de ánimo de las personas que les rodean sí les influye. Profesionales y familiares también creen que el ambiente y la sociedad en la que viven repercute en cómo gestionan sus duelos.

- Subcategoría de participación

- Participante 7: “Me enteré más tarde, entonces no fui a nada”.

- Profesional 3: “A mí sí me gustaría que con los chicos muchas veces se hubiera hablado de lo que es y lo que significa y ya está, abiertamente sin ningún tipo de tabú".

- Familiar 4: "Yo creo que tenemos miedo a que ellos sepan lo que es la muerte. A veces pienso que tenemos miedo a enfrentarles a eso ¿no?”.

- Subcategoría de ambiente

- Participante 10: "Entonces toda la familia en enero hicimos los 3 años que se murió mi abuela y estamos muy sensibles”.

- Profesional 2: "De todas maneras tenemos una sociedad que de la muerte es que se habla lo menos posible. Yo creo que las sociedades occidentales cuando más desarrollados estamos es más duro para nosotros el desapego de este mundo, tengo la impresión”.

- Profesional 5: "Las personas del medio rural han vivido la muerte de manera mucho más cercana que aquí en la ciudad”.

\subsection{Categoría de Desarrollo personal}

El proceso de duelo de las personas con DI depende de su personalidad, su capacidad y de la madurez que tengan. Los participantes con DI, en su mayoría, no han sabido definir el término duelo y a los tres grupos se les ha preguntado sobre recibir una formación futura. Las personas con discapacidad reconocen no haber hablado nunca sobre este tema aunque se muestran dudosos sobre si querer recibir o no esa formación. Profesionales y familiares creen que sería una buena opción que podría 
mejorar su calidad de vida, pero el grupo de profesionales duda de su efectividad y apunta que sería cuestión de cómo plantearlo.

- Subcategoría de educación/formación

- Participante 1: "El duelo es enfrentarse a otras personas, bueno, enfrentarse a algo".

- Participante 2: "Yo, ni idea".

- Profesional 3: "Es probable que el $90 \%$ de las personas con discapacidad que tenemos en nuestro centro no hayan oído hablar de la muerte de forma abierta nunca, yo creo que todo lo que sea hablar... el tema se tendría que incluir de forma transversal”.

- Profesional 2: "Sí, y es intentar una cosa más y, bueno, pues ver si eso resulta, eso es verdad. Yo dudo bastante de los resultados, de lo que pueda servir, pero, vamos, no estaría en contra en absoluto de que eso se hiciera”.

- Familiar 4: "Yo pienso que la formación sobre la muerte sí es buena, que sepan que está ahí y que es realidad".

- Familiar 7: "Sí, o algún tipo de estrategia para poderse controlar en esos casos”.

\subsection{Categoría de bienestar material}

Algunos de los participantes afirman tener objetos de la persona fallecida en su propiedad, y les han servido para ayudarles.

- Subcategoría de objetos y propiedades

- Participante 8: "Por ejemplo, mis padres me ayudaron dejándome cosas o recuerdos de él”.

- Participante 10: "Pero lo único que han hecho, han cogido, eh... y mi tío me dio las joyas de ella y tal, y tengo imágenes de ella”.

\subsection{Categoría de autodeterminación}

Los familiares toman la decisión de comunicar o no la noticia del fallecimiento de un ser querido, aunque algunos participantes con DI dicen ser ellos quienes eligen acudir o no a un funeral. En estos casos la asociación respeta siempre la decisión del familiar y actúa en consecuencia. Sin embargo, en los casos en los que es un compañero o alguna otra persona del centro quien fallece, se comunica desde allí y son las personas con DI quienes de forma independiente se unen y comparten sus sensaciones.

- Subcategoría de decisiones/elecciones

- Participante 9: "Yo por ejemplo cuando falleció el profesor de aquí yo no fui al entierro porque sé que lo paso mal, por eso”. 
- Participante 10: “Cuando murió mi abuela mi padre me estuvo diciendo, 'ven a verla, ven a verla' y yo dije que no la quería ver".

- Profesional 7: "Es la familia quien decide si se le dice o no, siempre".

- Subcategoría de valores

- Profesional 8: "Cuando fallece un compañero lo llevan fatal, muy muy mal y se unen entre ellos".

\subsection{Categoría de Derechos}

Como ya se ha comentado anteriormente algunos de los participantes con DI no fueron informados de la muerte de un ser querido y respecto a esto hay un debate abierto. La mayoría de los participantes cree que la persona con discapacidad tiene derecho, igual que el resto, de conocer esta noticia, aunque otros opinan que depende del caso y de la persona. Están de acuerdo en que tienen el derecho de hablar del tema abiertamente en las aulas y de recibir algún tipo de información que pueda servir de utilidad.

- Subcategoría de derecho a la información

- Profesional 2: "Yo en algún caso dudo. Dudo sinceramente que sea necesario decírselo. Hombre, yo entiendo que como norma deben saberlo, pero luego hay situaciones que es lo que digo yo, cada persona es un duelo, entonces...”.

- Familiar 3: "Yo creo que a nadie se le debe negar la realidad existente".

- Subcategoría de derecho a la educación

- Participante 1: "No, de la muerte nunca habíamos hablado aquí”.

- Profesional 3: "La verdad que yo pienso que cuanto más conozcas pues mejor”.

- Profesional 2: "Serviría educar, pero educar es una palabra muy grande como para decir si mejora la calidad de vida de las personas. Yo no tengo claro que educar en el duelo... depende cómo y para quien. Ahora, formar y quitar los tabúes sobre este tipo de cosas sí creo que mejora la calidad de vida de cualquiera”.

- Familiar 5: "Deberíamos enseñarles que la muerte es normal, que nacemos y que morimos".

- Familiar 8: "Contestarles y darles todas las explicaciones que tengas en tu mente”.

- Subcategoría de derecho a la privacidad/intimidad

- Participante 9: "Me encierro en la habitación y me pongo la música a tope y como que me quiero olvidar de todo, de lo que he vivido, de lo que me ha pasado y de lo que me pasa”.

- Participante 9: "A veces te agobian demasiado y le das más a la cabeza y están ahí todo el rato detrás de ti y eso a veces cansa”. 


\section{Discusión}

En este apartado se ponen en relación los resultados obtenidos y los objetivos planteados, y las principales conclusiones extraídas tras el análisis y el procedimiento realizado.

Los resultados obtenidos tienen especial relevancia ya que han permitido hacer visible la falta de formación e información que existe no solo en las personas con DI, sino en su entorno más próximo, en lo referente al duelo. A través de los resultados, también se pone de manifiesto la necesidad de que familias y asociaciones trabajen conjuntamente sobre este tema, en una misma línea y de manera individualizada, ya que cada persona requiere de unas estrategias diferentes en función de su caso. En cuanto al nivel y necesidad de formación, se ha observado una inexistencia de la misma, tanto en el terreno familiar como educativo.

El grado de discapacidad, la sociedad, el ambiente, el entorno, la religión y el concepto de muerte que cada uno tenga son factores que influyen definitivamente en la manera de vivir un duelo. Parece que las personas con discapacidad no piensan en su propia muerte ni se la plantean y, en general, no saben lo que es el duelo. Aun así, parece confirmarse que las personas con discapacidad experimentan procesos de duelo de una forma u otra (Rodríguez, 2012), y con más o menos resiliencia o problemas de salud asociados.

Llama la atención que las personas con discapacidad dicen haberse sentido tristes y haberlo expresado mediante el llanto, y, sin embargo, padres y profesionales afirman lo contrario. Según ellos, las personas con discapacidad, en su mayoría, no exteriorizan sentimientos ni saben expresarlos, condiciones que normalmente se han asociado a la discapacidad (Wiese, Stancliffe, Read, Jeltes y Clayton, 2015).

La decisión de comunicar la muerte de un ser querido a las personas con discapacidad recae en la familia y son ellos quienes informan a la asociación de sus preferencias con respecto a cómo tratar el tema con el usuario. En ocasiones, los comunicados se hacen desde el centro, a petición de las familias por miedo a posibles reacciones (Ruiz y Sainz, 2008). También se puede ver en los resultados que, otras veces, son el aspecto físico o el ver un familiar hospitalizado los indicadores para que la propia persona con discapacidad intuya un fallecimiento próximo.

En cuanto a ocultar la información o contar a la persona con discapacidad la noticia de que un familiar ha fallecido, no existe una única conclusión. Como norma, parece aceptado que todo el mundo tiene derecho a ser partícipe de un hecho como este, pero en la práctica no siempre se cumple. Tal y como comentan Ruiz y Sainz (2008), no se enseña a desarrollar un proceso de sufrimiento normal en este colectivo, aunque depende de casos y personas. En algunos casos, las personas con discapacidad dejan de formar parte de los actos fúnebres debido a ese ocultamiento. Aun así, siguen viendo a sus padres como las principales figuras de apoyo cuando fallece un ser querido.

En base a los resultados, se puede concluir que este colectivo no tiene recursos de afrontamiento o estrategias ante un duelo. Recurren a la soledad, no mantienen conversaciones profundas con nadie y, a veces, son las familias quienes "inventan" esas estrategias para explicar un fallecimiento. Es, precisamente, la búsqueda de esos 
recursos lo que va a favorecer la inclusión del colectivo en la sociedad (Martín y Sánchez, 2015), ya que en ocasiones pueden mostrar comportamientos inmaduros y no acordes con su edad.

Nunca han tratado el tema en ASPANIAS, y hay quienes opinan que podría incluirse de manera transversal en la formación y quienes se muestran dudosos de la efectividad que pudiera tener. En 2012, Rodríguez y colaboradores plantean como otra alternativa la pedagogía de la muerte, ya que tener más formación les ayudaría a crearse su propio autoconcepto y tener otra visión de sí mismos (Rodríguez et al., 2015). Tienen el derecho de intentarlo sin negarles la posibilidad de sufrir (Romero, 2013), aunque algunos duden de los resultados.

Por tanto, y en función de todo lo anterior, queda un debate abierto sobre si se debe ocultar la noticia de un fallecimiento o no a una persona con DI, cuya función depende siempre de la decisión de la familia. Sin embargo, tanto ellos como los profesionales parecen estar dispuestos a incluir formación sobre el tema de manera transversal y práctica debido a su inexistencia en la actualidad.

Esa formación permitiría al colectivo generar una búsqueda de recursos que facilitara la expresión de sentimientos, y el tener una visión real del ciclo vital sobre el que reflexionar y desarrollar su autoconcepto. Además, dotar de esos recursos podría ser útil para evitar ciertos problemas de comportamiento o de salud una vez que fallece un ser querido, y también contribuiría a generar actitudes más maduras para enfrentarse a ello.

Aun así, parece que, en general, este es un tema que resulta interesante pero que no se acoge con agrado en la sociedad y que sigue siendo tabú. Esta puede ser la causa de que no se repare en él, ni se trate abiertamente, y mucho menos con personas con DI. Por ello, se hace necesario encontrar la forma de acercarles el tema de una manera natural desde el ámbito educativo, aunque hay que ser conscientes de que, para poder avanzar en ello, y desarrollar una formación adecuada, hay que seguir investigando.

Se trata de hacer partícipes a las personas con DI de una realidad inevitable, a la que tarde o temprano se han de enfrentar, y darles la oportunidad de hacerlo con las mismas posibilidades que el resto de personas, a través de información a la que muchos de ellos no han tenido nunca acceso, ni en el terreno familiar, ni en el entorno educativo.

En cuanto a las limitaciones encontradas a la hora de realizar el trabajo, cabe destacar, en primer lugar, el escaso número de investigaciones y bibliografía reciente existente sobre el tema, lo cual ha dificultado la búsqueda de información. En segundo lugar, la selección de la muestra no ha seguido un procedimiento aleatorio y además es pequeña, por lo que sería necesario llevar a cabo una ampliación de la misma. También ha dificultado en cierto modo el proceso el depender de la disponibilidad de la asociación para desarrollar los grupos de discusión, ya que es una asociación integrada por un elevado número de personas. Por último, ha sido necesario tener en cuenta, en todo momento, que algunas de las opiniones dadas durante el desarrollo de las sesiones han podido ser exageradas o distorsionadas en función del tipo de personalidad (sobre todo en el grupo de los usuarios con DI), o estar bajo algún tipo de sesgo, por miedo de los participantes a expresarse o exponer ciertos aspectos en público.

Ediciones Universidad de Salamanca / CC BY-NC-ND

Siglo Cero, vol. 49 (4), n. ${ }^{\circ}$ 268, 2018, octubre-diciembre, pp. 51-68

$$
-66-
$$



EVA DOMINGO BENITO, JOSÉ LUIS CUESTA GÓMEZ Y SERGIO SÁNCHEZ FUENTES

Por otro lado, dentro de las líneas de investigación futuras, la principal es la elaboración de una guía de buenas prácticas de duelo, que incluya pautas y recursos, tanto a nivel preventivo como paliativo para familias, profesionales y personas con DI. Una segunda línea sería la creación de una propuesta educativa transversal, donde se incluya el tema de la muerte, por ejemplo, a través de la inteligencia emocional o los valores. Por último, una tercera línea podría ser el planteamiento del estudio de otros tipos de duelo en este colectivo, como el de las pérdidas materiales o evolutivas.

\section{Referencias bibliográficas}

American Association of IntellectualandDevelopmentalDisabilities(2011).Verdugo, M. Á. (trad.). Discapacidad intelectual: definición, clasificación y sistemas de apoyo. Madrid: Alianza.

BAÑA, M. (2015). The role of the familiy in the quality of life and self-determination of people with autistic spectrum disorder. Ciencias Psicológicas, 9 (2), 323-336. Recuperado de http:// www.scielo.edu.uy/pdf/cp/v9n2/v9n2a09.pdf.

Barbour, R. (2013). Los grupos de discusión en Investigación Cualitativa. Madrid: Ediciones Morata.

Brickell, C. y MuniR, K. (2008). El duelo y sus complicaciones en las personas con discapacidad intelectual. Revista Sindrome de Down, 25 (2), 68-76. Recuperado de Down Cantabria. http://www.downcantabria.com/revistapdf/97/68-76.pdf.

Gulbenkoglu, H. (2007). Supporting people with disabilities coping with grief and loss. Melbourne (Australia): Scope. Recuperado de http://www.easyhealth.org.uk/sites/default/ files/Supporting \%20people $\% 20$ with $\% 20$ disabilities $\% 20$ coping $\% 20$ with $\% 20$ grief $\% 20$ and $\% 20$ loss.pdf.

KitZingeR, J. (1995). Introducing focus group. British medical Journal (BMJ), 311 (7000), 299302. Recuperado de https://www.researchgate.net/profile/Jenny_Kitzinger/publication/ 15566389_Qualitative_Research_Introducing_Focus_Groups/links/00b7d52951foa 07aab000000/Qualitative-Research-Introducing-Focus-Groups.pdf.

Martín, M. V. y Sánchez, M. C. (2016). Análisis cualitativo de tópicos vinculados a la calidad de vida en personas con discapacidad. Ciência E Saúde Coletiva, 21 (8), 2365-2374. doi: 10.1590/1413-81232015218.04182016.

Martínez, M. (2009). Weft-QDA. Manual del usuario en español. Recuperado de http://www. ceciliamartinez.com.ar/Weft\%20QDA\%20manual\%201.0.pdf.

McEvoy, J., Machale, R. y Tierney, E. (2012). Concept of death and perceptions of bereavement in adults with intellectual disabilities. Journal of Intellectual Disability Research, 56 (2), 191-203. doi: 10.1111/j.1365-2788.2011.01456.x.

Roberts, J., Thomas, A. y Morgan, J. (2016). Grief, Bereavement, and Positive Psychology. Journal of Counseling and Psychology, 1 (1), 1-19. Recuperado de Digital Commons @ Gardner-Webb University.

Rodríguez, P. (2012). Pedagogía de la Muerte en personas con discapacidad intelectual. Elaboración, aplicación y evaluación de un programa educativo (tesis doctoral). Universidad Autónoma de Madrid, Facultad de Formación de Profesorado y Educación, Departamento de Didáctica y Teoría de la Educación.

Rodríguez, P., De la Herrán, A. y De la Cortina, M. (2012). Antecedentes de Pedagogía de la Muerte en España. Enseñanza E Teaching, Revista Interuniversitaria de Didáctica, 
30 (2), 175-195. Recuperado de https://www.uam.es/personal_pdi/fprofesorado/agustind/ textos/antecedentesPMEsp.pdf.

Rodríguez, P., De la Herrán, A. e Izuzquiza, D. (2013a). Orientaciones pedagógicas para el acompañamiento educativo por duelo a personas adultas con discapacidad intelectual. Teoría de la Educación, 25 (1), 173-189. Recuperado de Ediciones Universidad de Salamanca. file://C:/Users/usuario/Downloads/11157-40932-1-PB\%20(2).pdf.

Rodríguez, P., De la Herrán, A. e Izuzquiza, D. (2013b). «Y si me muero... ¿ ¿ónde está mi futuro?» Hacia una educación para la muerte en personas con discapacidad intelectual. Educación XX1, 16 (1), 329-350. doi: 10. 5944/educxx1.16.1.729.

Rodríguez, P., Izuzquiza, D. y De la Herrán, A. (2015). Concept of death in young people with intellectual disability: a contribution to the pedagogy on death. Siglo Cero, 46 (1), 253, 67-80. Recuperado de Ediciones Universidad de Salamanca. https://www.uam.es/personal_pdi/fprofesorado/agustind/textos/concept $\% 20$ of $\% 20$ death $\% 20$ in....pdf.

Romero, V. (2013). Tratamiento del duelo: exploración y perspectivas. Psicooncología, 10 (2), 377-392. doi: 10.5209/rev_PSIC.2013.v10.n2-3.43456.

Ruiz, N. y SAinz, F. (2008). Apoyo en el proceso de duelo de personas con discapacidad intelectual. Salamanca: Instituto Universitario de Inteligencia. Recuperado dehttp://sid.usal. es/20846/8-4-1.

Schalock, R. (1996). Reconsidering the conceptualization and measurement of quality of life. En R. L. Schalock (Ed.), Quality of life: Conceptualization and Measurement (pp. 123139). Washington: American Association on Mental Retardation.

Schalock, R. y Verdugo, M. Á. (2002). Calidad de vida. Manual para profesionales de la educación, salud y servicios sociales. Madrid: Alianza Editorial.

Schalock, R. y Verdugo, M. Á. (2007). El concepto de calidad de vida en los servicios y apoyos para personas con discapacidad intelectual. Siglo Cero, 38 (4), 21-36. Recuperado de http://sid.usal.es/idocs/F8/ART10366/articulos2.pdf.

Tizón, J. (2004). Pena, pérdida, duelo. Vivencias, investigación y asistencia. Barcelona: RBA, D.L.

Wiese, M., Roger, J., Stancliffe, S. R., Jeltes, G. y Clayton, J. M. (2015). Learning about dying, death, and end-of-life planning: Current issues informing future actions. Journal of intellectual and developmental disability, 40 (2), 230-235. doi: http://dx.doi.org/10.3109/1 3668250.2014 .998183 . 